\title{
Dasatinib-induced nephrotic syndrome in a patient with chronic myelogenous leukemia: a case report
}

\author{
Shoko Ochiai ${ }^{1 *}$, Yuji Sato², Akihiro Minakawa', Akihiro Fukuda² and Shouichi Fujimoto 2,3
}

\begin{abstract}
Background: Dasatinib is a second-generation tyrosine kinase inhibitor that is indicated for the treatment of patients with chronic myeloid leukemia. Here, we report the case of a man with nephrotic syndrome that was caused by dasatinib.

Case presentation: A 40-year-old man with chronic myeloid leukemia was referred to our hospital because of proteinuria 1 month after dasatinib therapy was introduced. A percutaneous kidney biopsy was performed, diffuse glomerular endothelial injury and effacement of the foot process were noted, and the patient was diagnosed with dasatinib-induced nephrotic syndrome. Additionally, in an electron microscopy study, randomly arranged fibrils were observed in the mesangial and subendothelial regions. Switching from dasatinib to nilotinib led to a decrease in the proteinuria level, from 12 to $0.6 \mathrm{~g} / \mathrm{g}$ creatinine, within 2 weeks. The patient was discharged from our department on the 25th day after hospitalization, without any drug aftereffects.
\end{abstract}

Conclusions: Drug-related nephrotic syndrome should be considered when nephrotic syndrome develops during treatment with dasatinib.

Keywords: Drug-related nephrotic syndrome, Tyrosine kinase inhibitor, Dasatinib, Fibrillary glomerulonephritis, Nephrotic syndrome, Vascular endothelial growth factor

\section{Background}

Chronic myelogenous leukemia (CML) is an important hematological tumor that is characterized by the BCR-ABL chimera gene and occurs in 15 to $20 \%$ of adults with leukemia [1]. CML slowly progresses in the first 4-6 years after onset, but when it progresses to the blastic stage, it is acute and lethal. The BCR-ABL gene is formed by mutual translocation between c-ABL on chromosome 9 and BCR on chromosome 22, which activates tyrosine kinase continuously, leading to leukemia-cell proliferation [2]. Therefore, tyrosine kinase inhibitors (TKIs) are known to be"silver bullet" therapies that dramatically improve the prognosis of patients with CML. Dasatinib, a second-generation TKI, is available in Japan and leads to a higher remission rate of CML than

\footnotetext{
* Correspondence: shouko_ochiai@med.miyazaki-u.ac.jp

${ }^{1}$ Department of Internal Medicine, Division of Circulatory and Body Fluid Regulation, Faculty of Medicine, University of Miyazaki, 5200 Kihara, Kiyotake, Miyazaki 889-1692, Japan

Full list of author information is available at the end of the article
}

former-generation TKIs do [3]. However, recent reports suggested that renal adverse effects, including nephrotic syndrome, could occur after TKIs are used [4-10]. Here, we report the case of a CML patient in whom nephrotic syndrome was induced by dasatinib, along with a short literature review.

\section{Case presentation}

A 40-year-old Japanese man was admitted to another hospital with edema of both lower extremities, a feeling of abdominal fullness, and shortness of breath upon exertion. A physical examination showed a giant splenomegaly that reached the pelvic cavity and hepatomegaly. The patient's leg edema was thought to be caused by the giant splenomegaly. A blood test showed an elevated white blood cell count of $480,000 / \mu \mathrm{L}$. According to a bone marrow examination, he was diagnosed with CML, and dasatinib at a daily dose of $100 \mathrm{mg}$ was prescribed.

CML was improved with the use of dasatinib therapy, with a decreased volume of splenomegaly and leg edema.

(c) The Author(s). 2019 Open Access This article is distributed under the terms of the Creative Commons Attribution 4.0 International License (http://creativecommons.org/licenses/by/4.0/), which permits unrestricted use, distribution, and 
However, 1 month after dasatinib was introduced, heavy proteinuria (urinary protein-creatinine ratio of $8.93 \mathrm{~g} / \mathrm{g}$ creatinine $[\mathrm{g} / \mathrm{gCr}])$ appeared, accompanied by a low serum albumin level of $2.3 \mathrm{~g} / \mathrm{dL}$. Two months after dasatinib was introduced, the drug was transiently stopped because of pancytopenia, and then the drug was restarted. The patient was referred to our hospital for a further investigation for nephrotic syndrome after dasatinib was used for 3 months.

On admission, a physical examination showed a blood pressure of $121 / 70 \mathrm{mmHg}$, pulse of $56 / \mathrm{min}$, temperature of $36.5^{\circ} \mathrm{C}$, and respiratory rate of $16 / \mathrm{min}$, as well as slight splenomegaly and lower leg edema. A complete blood count test showed a white blood cell count of $11,500 / \mu \mathrm{L}$, hemoglobin level of $13.2 \mathrm{~g} / \mathrm{dL}$, and platelet count of $132,000 / \mu \mathrm{L}$. Blood chemistry and serology tests showed a serum creatinine level of $0.87 \mathrm{mg} / \mathrm{dL}$ (estimated glomerular filtration rate of $78.4 \mathrm{~mL} / \mathrm{min} / 1$. $73 \mathrm{~m}^{2}$ ), serum albumin level of $3.08 \mathrm{~g} / \mathrm{dL}$, total cholesterol level of $287 \mathrm{mg} / \mathrm{dL}$, and low-density lipoprotein cholesterol level of $166 \mathrm{mg} / \mathrm{dL}$. In addition, antinuclear antibody and viral hepatitis were not evident in a serological test. A spot urine examination showed protein/ creatinine ratio of $12.2 \mathrm{~g} / \mathrm{gCr}$, urinary protein $3+$, and hematuria 1+. Urine sediment showed 5-9 red blood cells/high-power field and hyaline casts. Ultrasonography showed that the kidneys were almost normal-sized. A percutaneous kidney biopsy was performed, and light microscopy with periodic acid-Schiff staining revealed diffuse and global endothelial cytoplasm expansion that was accompanied by focal duplication of the glomerular basement membrane (Fig. 1a). However, spike formation was not evident in the periodic acid-methenamine silver-stained section test (Fig. 1b). An immunofluorescence study did not show deposition of immunoglobulin or its complement. Electron microscopy revealed swelling of the endothelial cells (Fig. 1c) and effacement of the podocyte foot process (Fig. 1d). In addition, randomly arranged fibrils $(10-20 \mathrm{~nm})$ were observed in the mesangial, subepithelial, and subendothelial regions (Fig. 1d and e), but their distribution was relatively focal. AA amyloidosis was

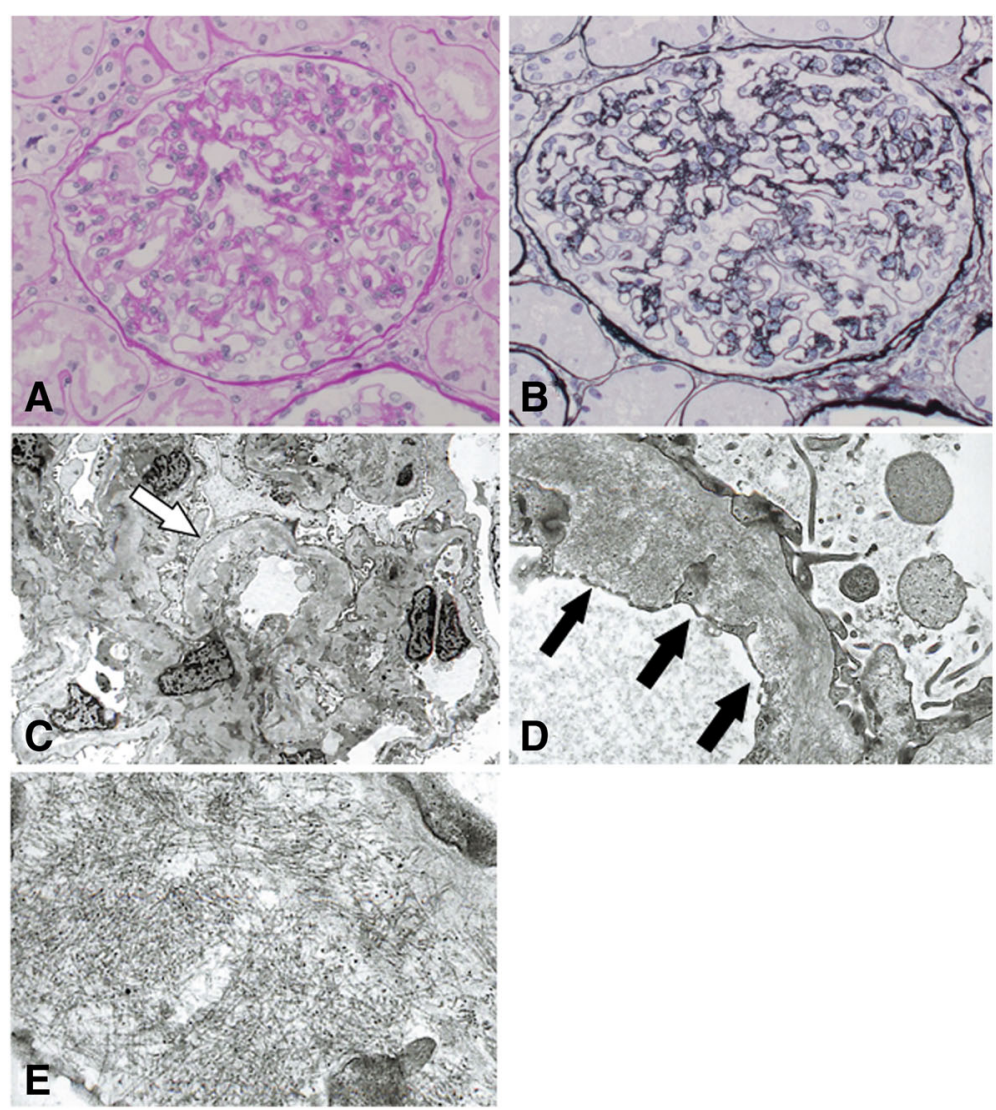

Fig. 1 Light microscopic findings with periodic acid-Schiff staining (a) revealed diffuse and global endothelial cytoplasm expansion accompanied by focal duplication of the glomerular basement membrane. Spike formation was not evident on the periodic acid-methenamine-silver stained section (b). Electron microscopy revealed swelling of the endothelial cells (c, arrow) and effacement of the podocyte foot process (d). In addition, randomly arranged fibrils (10-20 nm, arrows) are observed in the mesangial, subepithelial and subendothelial regions (d and e). Original magnification $\mathbf{a}: \times 400, \mathbf{b}: \times 400, \mathbf{c}: \times 1000, \mathbf{d}: \times 5000, \mathbf{e}: \times 15000$ 
deemed unlikely because of negative Congo-red staining and immunohistochemistry (Fig. 2a). In addition, negative immunohistochemistry for DNAJB9 did not suggest the diagnosis of fibrillary glomerulonephritis (Fig. 2b). We thought that these renal histological changes were caused by dasatinib, but the cause and diagnosis of fibril were not evident.

We switched from dasatinib therapy to nilotinib at a daily dose of $600 \mathrm{mg}$. The patient's spot urine protein/ creatinine ratio improved to $0.63 \mathrm{~g} / \mathrm{gCr}$ and his hematuria disappeared within 2 weeks. His renal function did not worsen. We concluded that the main cause of nephrotic syndrome was dasatinib because only switch of the drug improved the patient's proteinuria. He was discharged from our department on the 25th day after hospitalization, without any aftereffects.

\section{Discussion and conclusions}

We reported the case of a patient with nephrotic syndrome that was possibly induced by dasatinib treatment for CML. Dasatinib-related proteinuria was reported in $18 \%$ of participants in a phase I dose-escalation and pharmacokinetic study to treat patients with advanced solid tumors [11]. Five case reports of nephrotic syndrome that was caused by dasatinib are available, three of which are on adults and the others are on children [4-8] (Table 1). In all cases, discontinuation or reduction of the dose of dasatinib or a switch to a first-generation TKI improved proteinuria. Hirano et al. proposed that the severity of proteinuria was dose-dependent, because reducing the dose by half was efficient in their study [5]. A kidney biopsy was performed on three of their study subjects, and the study revealed that both endothelial cell injury and effacement of the foot process were common findings, while the severity of effacement of the foot process differed among the cases.
Dasatinib is a second-generation TKI, as well as a multi-kinase inhibitor, that inhibits not only the BCR-ABL gene but also other kinases such as the platelet-derived growth factor receptor beta, KIT, and SRC kinase family [12]. Dasatinib inhibits the SRC family of kinases (SFK) as well as the production of vascular endothelial growth factor (VEGF) indirectly through SFK [13]. VEGF is produced in podocytes, binds to the VEGF-2 receptor of endothelial cells with a paracrine effect, and maintains the cellular function and morphology [14]. In addition, as an autocrine effect, VEGF binds to the VEGF-2 receptor and sFlt-1 of its own podocyte, thereby controlling the cytoskeleton and slit diaphragm between the podocyte foot processes [14]. This is the most likely reason why VEGF inhibition by dasatinib causes podocyte and endothelial cell disorders that lead to nephrotic syndrome. Pfister et al. reported the histological characteristics induced by anti-VEGF therapy [15]. They described glomerular capillary microaneurysms and segmental semilunar hyalinoses were most frequently found in anti-VEGF therapy-induced glomerulopathy, but we could not see these changes in our case. However, some of the histological findings, such as endothelial cytoplasm expansion and double contours of glomerular basement membrane, were compatible with those reported by Pfister et al. Even for drugs with the same VEGF inhibition, the renal pathological changes caused by different drugs might not be the same. In our case, endothelial cell and podocyte injury might be reversible because proteinuria is decreased by discontinuing the drug or reducing the dose. First-generation TKIs are not capable of inhibiting VEGF $[16,17]$; therefore, switching to a first-generation TKI is another effective treatment method. Some people who use dasatinib have mild proteinuria and others experience progression to nephrotic syndrome, but the mechanism of various degrees of proteinuria is

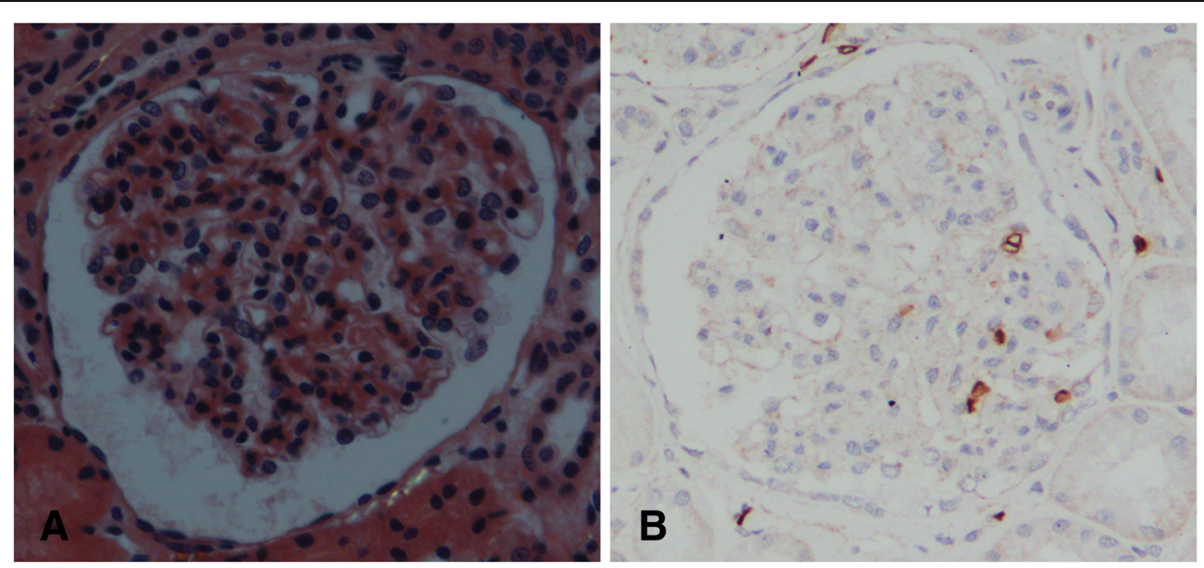

Fig. 2 Our case does not show glomerular staining for Congo red (a) and DNAJB9 (b) immunohistochemistry. (a, b, Original magnification $\times 400)$ 
Table 1 Clinical features of patients with dasatinib-induced nephrotic syndrome in previous case reports

\begin{tabular}{|c|c|c|c|c|c|c|c|c|c|}
\hline Case & Author & Patient & $\begin{array}{l}\text { Basal } \\
\text { hematological } \\
\text { disease }\end{array}$ & $\begin{array}{l}\text { Duration of } \\
\text { dasatinib } \\
\text { administration }\end{array}$ & $\begin{array}{l}\text { Urinary } \\
\text { protein } \\
\text { excretion }\end{array}$ & $\begin{array}{l}\text { Serum } \\
\text { creatinine } \\
(\mathrm{mg} / \mathrm{dL})\end{array}$ & Renal histology & Treatment & Prognosis \\
\hline 1 & Wallace $^{[4]}$ & $63, F$ & CML & 3 months & $3.9 \mathrm{~g} /$ day & 0.79 & $\begin{array}{l}\text { Focal foot process } \\
\text { effacement }\end{array}$ & $\begin{array}{l}\text { Switch to } \\
\text { imatinib }\end{array}$ & remission \\
\hline 2 & Hirano ${ }^{[5]}$ & $64, F$ & $\mathrm{Ph}+\mathrm{ALL}$ & 2 weeks & $3.9 \mathrm{~g} /$ day & 0.34 & NA & $\begin{array}{l}\text { Dose } \\
\text { reduction }\end{array}$ & remission \\
\hline 3 & Ruebner $^{[6]}$ & $3, F$ & CML & 17 months & $\mathrm{UP} / \mathrm{Ucr}=17 \mathrm{~g} / \mathrm{gCr}$ & 0.3 & $\begin{array}{l}\text { Focal foot process } \\
\text { effacement }\end{array}$ & Discontinue & remission \\
\hline 4 & $\operatorname{Lim} Y T^{[7]}$ & $5, M$ & $\mathrm{Ph}+\mathrm{ALL}$ & & $\mathrm{UP} / \mathrm{Ucr}=15.24 \mathrm{~g} / \mathrm{gCr}$ & NA & $\begin{array}{l}\text { Diffuse foot process } \\
\text { effacement }\end{array}$ & Discontinue & remission \\
\hline 5 & De Luca ${ }^{[8]}$ & $45, \mathrm{~F}$ & CML & 6 months & $4.0 \mathrm{~g} /$ day & 0.9 & NA & $\begin{array}{l}\text { Switch to } \\
\text { imatinib }\end{array}$ & remission \\
\hline 6 & Our case & $40, M$ & CML & 3 months & $5.7 \mathrm{~g} /$ day & 0.87 & $\begin{array}{l}\text { Endothelial cell injury and } \\
\text { foot process effacement }\end{array}$ & $\begin{array}{l}\text { Switch to } \\
\text { nilotinib }\end{array}$ & remission \\
\hline
\end{tabular}

Abbreviations: $C M L$ chronic myeloid leukemia, $P h+A L L$ Philadelphia-positive acute lymphoblastic leukemia, UP/UCr: urinary protein: urinary creatinine concentration ratio

unknown. However, massive proteinuria is caused by massive podocyte injury, not by endothelial cell injury $[18,19]$. The electron microscopy study of our case showed diffuse effacement of the foot process. We think this effacement caused massive proteinuria. Because endothelial cells could be more easily injured by the small doses of dasatinib than podocytes, short-term administration of dasatinib or a low dose of dasatinib may not cause nephrotic-range proteinuria, but cause only mild proteinuria. Then, an injury that progresses to the podocytes could cause a greater amount of proteinuria.

In addition, we found a glomerular deposit (called fibril) in the EM study, which was negative for a Congo-red staining, suggesting non-amyloid deposit. At first, we suspected the fibril may be consistent with a diagnosis of fibrillary glomerulonephritis (FGN), because the diameter of the fibril seen in this case was larger than that seen in amyloidosis $(\phi 10-20 \mathrm{~nm}$ vs $\phi 8-12$ $\mathrm{nm})$. FGN is observed in $0.6-1.0 \%$ of kidney biopsies in Europe and the United States [20, 21]. In general, there are reports that patients with FGN have a poor prognosis, and $44 \%$ of these patients experience end-stage renal disease [22]. FGN has been reported to be associated with systemic lupus erythematosus, Crohn's disease, Graves' disease, or gastric cancer [22]. However, previous reports of dasatinib-induced glomerular damage in CML patients has never reported dasatinib-induced deposits such as FGN [4-8]. Usually, in patients with FGN, the prevalent pathologic finding is mesangial expansion in light microscopy, and the deposition of IgG and/or C3 in immunofluorescence microscopy [21]. However, in our case, those findings were not seen, although there was an endothelial cell injury. In addition, the immunofluorescence microscopy result was negative in our case. DNAJB9 immunohistochemistry, which is specific for
FGN [23], was not positive. We found the fibril coincidentally after performing an electron microscopy study. Considering these results, we could not clarify the cause of fibril and the association between the fibril and dasatinib-induced renal damage. We deem that fibrils did not contribute much to proteinuria because the switch to a TKI dramatically decreased the amount of proteinuria. We believe that this case is worthy to report not only because of dasatinib-caused nephrotic syndrome but also because of the coexistence of fibrils in this case.

In summary, we reported a possible case of dasatinib-induced nephrotic syndrome in a patient with CML. Dasatinib has multi-kinase inhibition activity, unlike other TKIs, and it could injure podocyte and endothelial cells via the inhibition of VEGF. Dasatinib is a useful drug for treating CML, and we expected it to be used more frequently in the future. However, we should keep in mind that the drug's adverse effects, because they are reversible if early intervention is performed.

\section{Abbreviations \\ CML: Chronic myelogenous leukemia; Cr: Creatinine; EM: Electron microscopy; FGN: Fibrillary glomerulonephritis; SFK: SRC family kinase; TKI: Tyrosine kinase inhibitor; VEGF: Vascular endothelial growth factor}

\section{Acknowledgements}

We thank Satoshi Hisano for providing insightful suggestions for this report.

Funding

Not applicable.

Availability of data and materials

All data supporting the case are included in the manuscript.

Authors' contributions

SO, YS, AM, and AF clinically cared for the patient and participated in the acquisition of clinical data. SO, YS, and AF performed the renal biopsy. SO, YS, AM, AF, and SF analyzed the patient's clinical course and interpreted the data. SO wrote a draft of the manuscript and $Y S, A M, A F$, and SF revised it critically. All authors read and approved the final manuscript. 


\section{Ethics approval and consent to participate}

Not applicable.

\section{Consent for publication}

Written informed consent was obtained from the patient for the publication of this case report. A copy of the written consent form is available for review by the editor of the journal.

\section{Competing interests}

The authors declare that they have no competing interests.

\section{Publisher's Note}

Springer Nature remains neutral with regard to jurisdictional claims in published maps and institutional affiliations.

\section{Author details}

'Department of Internal Medicine, Division of Circulatory and Body Fluid Regulation, Faculty of Medicine, University of Miyazaki, 5200 Kihara, Kiyotake, Miyazaki 889-1692, Japan. ²Dialysis Division, University of Miyazaki Hospital, Miyazaki, Japan. ${ }^{3}$ Department of Hemovascular Medicine and Artificial Organs, Faculty of Medicine, University of Miyazaki, Miyazaki, Japan.

\section{Received: 13 April 2018 Accepted: 28 February 2019}

\section{Published online: 07 March 2019}

\section{References}

1. Siegel RL, Miller KD, Fedewa SA, Ahnen DJ, Meester RGS, Barzi A, et al. Colorectal cancer statistics, 2017. CA Cancer J Clin. 2017;67:177-93.

2. Goldman JM, Melo JV. Targeting the BCR-ABL tyrosine kinase in chronic myeloid leukemia. N Engl J Med. 2001;344:1084-6.

3. Tokarski JS, Newitt JA, Chang CY, Cheng JD, Wittekind M, Kiefer SE, et al. The structure of Dasatinib (BMS-354825) bound to activated ABL kinase domain elucidates its inhibitory activity against Imatinib-resistant ABL mutants. Cancer Res. 2006;66:5790-7.

4. Wallace E, Lyndon W, Chumley P, Jaimes EA, Fatima H. Dasatinib-induced nephrotic-range proteinuria. Am J Kidney Dis. 2013;61:1026-31.

5. Hirano T, Hashimoto M, Korogi Y, Tsuji T, Miyanaka K, Yamasaki H, et al. Dasatinib-induced nephrotic syndrome. Leuk Lymphoma. 2016;57:726-7.

6. Ruebner RL, Copelovitch L, Evageliou NF, Denburg MR, Belasco JB, Kaplan BS. Nephrotic syndrome associated with tyrosine kinase inhibitors for pediatric malignancy: case series and review of the literature. Pediatr Nephrol 2014;29:863-869.

7. Lim YT, Kim YJ, Park YH, Hah JO, Lee JM. A case of dasatinib-induced nephrotic syndrome in a child with Philadelphia chromosome positive acute lymphoblastic leukemia. Yonsei Med J. 2016;57:532-3.

8. De Luca ML, Carmosino I, Stefanizzi C, Campanelli M, De Angelis F, Cesini L, et al. Nephrotic proteinuria developed under dasatinib treatment in a patient with chronic myeloid leukemia: a case report and review of the literature. Ann Hematol Oncol. 2016;3:1106.

9. Takahashi D, Nagahama K, Tsuura Y, Tanaka H, Tamura T. Sunitinib-induced nephrotic syndrome and irreversible renal dysfunction. Clin Exp Nephrol. 2012;16:310-5.

10. Quintyne KI, Neenan T, Casserly L, Gupta R. Uncommon side effect with a commonly used targeted agent: sunitinib-induced nephrotic syndrome in a patient with metastatic renal cell carcinoma. BMJ Case Rep. 2014;28:2014.

11. Demetri GD, Lo Russo P, MacPherson IR, Wang D, Morgan JA, Brunton VG, et al. Phase I dose-escalation and pharmacokinetic study of dasatinib in patients with advanced solid tumors. Clin Cancer Res. 2009;15:6232-40.

12. Montero JC, Seoane S, Ocaña A, Pandiella A. Inhibition of Src family kinases and receptor tyrosine kinases by Dasatinib: possible combinations in solid tumors. Clin Cancer Res. 2011;17:5546-52.

13. Liang W, Kujawski M, Wu J, Lu J, Herrmann A, Loera S, et al. Antitumor activity of targeting SRC kinases in endothelial and myeloid cell compartments of the tumor microenvironment. Clin Cancer Res. 2010;16:924-35.

14. Advani A. Vascular endothelial growth factor and the kidney: something of the marvellous. Curr Opin Nephrol Hypertens. 2014;23:87-92.

15. Pfister F, Amann K, Daniel C, Klewer M, Büttner A, Büttner-Herold M. Characteristic morphological changes in anti-VEGF therapy-induced glomerular microangiopathy. Histopathology. 2018;73:990-1001.
16. Weisberg E, Manley PW, Breitenstein W, Bruggen J, Cowan-Jacob SW, Ray A, et al. Characterization of AMN107, a selective inhibitor of native and mutant Bcr-Abl. Cancer Cell. 2005;7:129-41.

17. Kim IK, Rhee CK, Yeo CD, Kang HH, Lee DG, Lee SH, et al. Effect of tyrosine kinase inhibitors, imatinib and nilotinib, in murine lipopolysaccharide-induced acute lung injury during neutropenia recovery. Crit Care. 2013;20:R114.

18. Wiggins RC. The spectrum of podocytopathies: a unifying view of glomerular diseases. Kidney Int. 2007;71:1205-14.

19. Sato Y, Wharram BL, Lee SK, Wickman L, Goyal M, Venkatareddy M, et al. Urine podocyte mRNAs mark progression of renal disease. J Am Soc Nephrol. 2009:20:1041-52.

20. Rosenstock JL, Markowitz GS, Valeri AM, Sacchi G, Appel GB, D'Agati VD. Fibrillary and immunotactoid glomerulonephritis: distinct entities with different clinical and pathologic features. Kidney Int. 2003;63:1450-61.

21. Fogo A, Qureshi N, Horn RG. Morphologic and clinical features of fibrillary glomerulonephritis versus immunotactoid glomerulopathy. Am J Kidney Dis. 1993:22:367-77.

22. Nasr SH, Valeri AM, Cornell LD, Fidler ME, Sethi S, Leung N, et al. Fibrillary glomerulonephritis: a report of 66 cases from a single institution. Clin J Am Soc Nephrol. 2011;6:775-84.

23. Nasr SH, Vrana JA, Dasari S, Bridoux F, Fidler ME, Kaaki S, et al. DNAJB9 is a specific Immunohistochemical marker for fibrillary glomerulonephritis. Kidney Int Rep. 2018;3:56-64

\section{Ready to submit your research? Choose BMC and benefit from:}

- fast, convenient online submission

- thorough peer review by experienced researchers in your field

- rapid publication on acceptance

- support for research data, including large and complex data types

- gold Open Access which fosters wider collaboration and increased citations

- maximum visibility for your research: over $100 \mathrm{M}$ website views per year

At $\mathrm{BMC}$, research is always in progress.

Learn more biomedcentral.com/submissions 